\title{
Distribution of Fluphenazine and Its Metabolites in Brain Regions and Other Tissues of the Rat
}

\author{
Manickam Aravagiri, Ph.D., Stephen R. Marder, M.D., Arthur Yuwiler, Ph.D.,
} K.K. Midha, Ph.D., D.Sc., Nora S. Kula, M.S., and Ross J. Baldessarini, M.D.

Rats were given 5,10 , or $20 \mathrm{mg} / \mathrm{kg}$ oral doses of fluphenazine (FLU) dihydrochloride daily for 15 days. FLU and its sulfoxide (FL-SO), 7-hydroxy (7-OH-FLU) and $N^{4}$-oxide (FLU-NO) metabolites were assayed in plasma, liver, kidney, fat, whole brain, and brain regions by specific and sensitive radioimmunoassays (RIA). Ail metabolites were detected in tissues at higher levels than in plasma, and the levels increased with dose. FLU was 10- to 27-fold higher in brain regions than in plasma. Brain vs plasma levels of FLU correlated more closely than levels of its metabolites. Liver contained the highest levels of all analytes at all doses. FLU-SO was the major metabolite in brain regions ( $24 \%$ to $96 \%$ of FLU) and accumulated in fat 43 to 75 times more than FLU. Levels of 7-OH-FLU and FLU-NO were very low in brain $(1 \%$ to $20 \%$ of FLU). FLU-SO and FLU-NO had only $1 \%$ to $3 \%$ the affinity for $D_{1}$ and $D_{2}$ receptors, but 7-OH-FLU had $20 \%$ the $D_{2}$ and $5 \%$ the $D_{1}$ affinity of FLU. The low affinity for dopamine receptors and low brain-levels of metabolites of FLU indicate that they are not likely to contribute importantly to pharmacologic responses of FLU. Also, the estimated relative "activity factor" for these compounds in the brain indicated that the contribution to neuropharmacologic activity by metabolites is less than 1\% of FLU. Consequently, clinical monitoring of plasma FLU alone may be sufficient. [Neuropsychopharmacology 13:235-247, 1995]
KEY WORDS: Dopamine receptors; Fluphenazine; Fluphenazine glucuronide; Fluphenazine-N-oxide; Fluphenazine sulfoxide; 7-Hydroxy-fluphenazine; Metabolism; Rat; Radioimmunoassay

From the Psychopharmacology Unit (MA, SRM, KKM), Mental Health Clinical Research Center, University of California at Los Angeles and the West Los Angeles Veterans Affairs Medical Center, BVMC-210, Wilshire and Sawtelle Blvds, Los Angeles, California: Neurobiochemistry Lab (AY), Department of Psychiatry, University of California at Los Angeles, Los Angeles, California; College of Pharmacy and Nutrition (KKM), University of Saskatchewan, Saskatoon, Saskatchewan, Canada; Department of Psychiatry and Neuroscience Program (NSK, RJB), Harvard Medical School, Boston; and Bipolar and Psychiatric Disorders Program and Laboratories for Psychiatric Research (NSK, RJB), Mailman Research Center, McLean Division of Massachusetts General Hospital, Belmont, Massachusetts.

Address correspondence to: Manickam Aravagiri, Ph.D., Psychopharmacology Unit, West Los Angeles VAMC, Bldg 210 RM 4, 11301-Wilshire Blvd, Los Angeles, CA 90073.

Received December 20, 1994; revised March 28, 1995; accepted April 5,1995
Fluphenazine (FLU), a piperazinyl phenothiazine neuroleptic (Figure 1), is widely used in the treatment of psychotic illnesses. It is commonly administered $\mathrm{PO}$ or IM as the dihydrochloride, or IM as the long-acting decanoate or enanthate esters in an oily vehicle. The metabolism of FLU is complex. It is metabolized extensively by aromatic hydroxylation, $\mathrm{S}$ - and N-oxidation, $\mathrm{N}$-desalkylation, and glucuronidation (Ebert and Hess 1965; Dreyfuss and Cohen 1971; Dreyfuss et al. 1971; Breyer et al. 1974a, 1974b; Gaertner et al. 1974, 1975; Curry et al. 1979). The sulfoxide (FLU-SO), $\mathrm{N}^{4}$-oxide (FLU-NO) and 7-hydroxy (7-OH-FLU) metabolites of FLU (Figure 1) are found in substantial levels in the plasma of patients treated with PO or IM preparations of FLU (Marder et al. 1989). FLU-SO, FLU-NO, and 7-OH-FLU have been reported to have antidopaminergic activity themselves, with 7-OH-FLU metabolite being the most potent among them (Yamada and Furu- 
Figure 1. Fluphenazine and its metabolites: chemical structures of fluphenazine (FLU; MW $=437.5)$, fluphenazine sulfoxide (FLU-SO; MW $=453.5$ ), fluphenazine $\mathrm{N}^{4^{\prime}}$-oxide (FLU-NO; $\mathrm{MW}=453.5)$, and 7-hydroxyfluphenazine (7$\mathrm{OH}-\mathrm{FLU} ; \mathrm{MW}=453.5$ ).

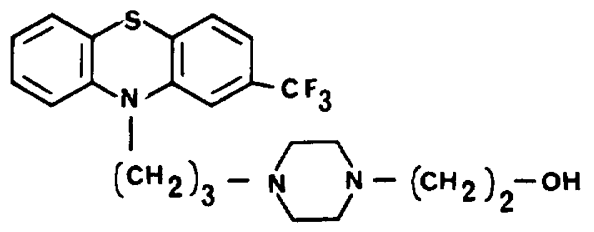

FLUPHENAZINE (FLU)

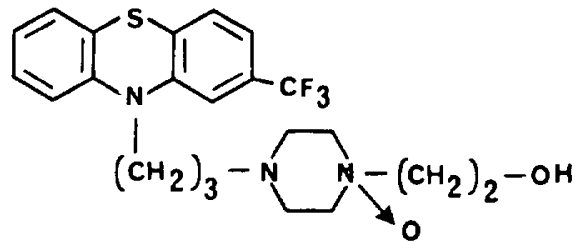

FLUPHENAZINE $\mathrm{N}^{4^{\prime}}$-OXIDE

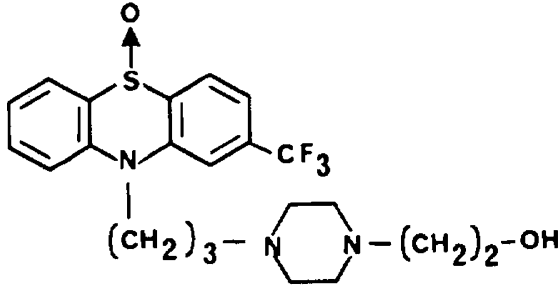

FLUPHENAZINE SULFOXIDE (FLU-SO)

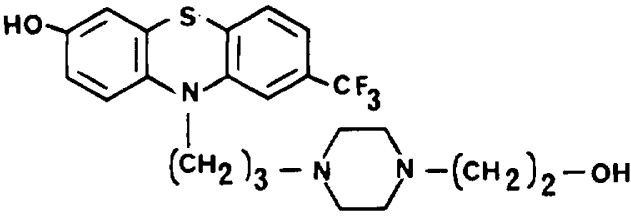

7-HYDROXYFLUPHENAZINE (7-OH-FLU) kawa 1980; Lewis et al. 1983, Hals and Dahl 1984, Morel et al. 1987). Accordingly, these metabolites of FLU may contribute to its pharmacologic effects by interactions at dopaminergic or other brain receptors such as the $5 \mathrm{HT} 2$, and $\alpha_{1}$-adrenergic receptors.

Clinically encountered plasma concentrations of antipsychotic agents, including FLU, vary by $10-$ to $100-$ fold in psychotic patients (Van Putten et al. 1991). Also, clinical responses are highly variable among patients and over time (Harris et al. 1982; Dahl 1986; Midha et al. 1987; Baldessarini et al. 1988). Attempts to correlate plasma levels of most neuroleptics with clinical responses generally have been inconsistent or inconclusive. Variations in absorption or hepatic clearance contribute to the wide variations in plasma levels of such agents (Van Putten et al. 1991; Koreen et al. 1994). As concentrations of neuroleptics at active sites in the brain presumably are related to their neuropharmacologic effects, regional variations in the distribution of neuroleptics and/or their metabolites among brain regions may contribute to variations in their actions.

Sunderland and Cohen (1986) found wide variations in the concentrations, determined by radio receptor assay, of several high- and low-potency neuroleptics in rat brain. With several high-potency antipsychotics, including haloperidol and FLU, brain-to-plasma level ratios were as high as 20 to 40 . These results were later verified by a liquid chromatographic method (Tsuneizumi et al. 1992). Concentrations of low-potency antipsychotics, such as chlorpromazine, thioridazine and their metabolites, and the ratio of their brain:se- rum levels also varied but tended to be lower than the high-potency agents (Swendsen and Bird 1986; Tsuneizumi et al. 1992). Concentrations of clozapine, another low-potency antipsychotic drug, were approximately 24-fold higher in rat brain than serum (Baldessarini et al. 1993). Concentrations of its N-desmethyl and $\mathrm{N}$-oxide metabolites in brain were insignificant as compared to clozapine, although these metabolites were present in serum ( $30 \%$ to $60 \%$ of serum clozapine). Although blood-brain distribution has been investigated for the metabolites of some low-potency antipsychotics (Alfredsson et al. 1977; Tsuneizumi et al. 1992; Baldessarini et al. 1993), there is little information available on the tissue distribution of metabolites after the administration of FLU.

Our previous investigations found that substantial levels of the sulfoxide, $\mathrm{N}^{4^{\prime}}$-oxide and 7-hydroxy metabolites of FLU were present in plasma of patients treated with oral FLU (Marder et al. 1989; Van Putten et al. 1991). Whereas the blood-brain distribution of FLU in the rat has been investigated (Sunderland and Cohen 1986; Tsuneizumi et al. 1992), the distribution of its major metabolites in brain has not been reported. In an early report, Dreyfuss et al. (1971) studied the distribution of FLU and its metabolites in dogs and monkeys using ${ }^{14} \mathrm{C}$-labeled FLU. High concentrations of total radioactivity following ${ }^{14} \mathrm{C}$-FLU were found in liver, kidney, and brain, but levels of individual metabolites were not reported.

The current study addresses the following questions: Do FLU metabolites reach the rat brain? What 
are the levels of FLU and its metabolites in various rat brain regions? Is there preferential localization of some of these compounds within brain regions? How do brain levels compare to simultaneous plasma levels? Are tissue levels of FLU and its metabolites dose-dependent? Do FLU metabolites have affinity for the major dopamine receptors in rat striatal membranes and could they possibly contribute to the clinical effects of FLU?

\section{MATERIALS AND METHODS}

\section{Chemicals}

Authentic samples of FLU, FLU-SO, 7-OH-FLU, and FLU-NO were generously donated by Bristol MyersSquibb Labs (New Brunswick, NJ), and FLU-glucuronide was synthesized by an immobilized enzyme technique (Jackson et al. 1991). All solvents and chemicals were liquid chromatographic grade or reagent grade (Fisher Scientific, Tustin, CA) and used without further purification. Bovine serum albumin (BSA), dextran, and activated charcoal were purchased from Sigma Chemical Co (St Louis, MO). Side chain $\mathrm{N}^{4^{\prime}}$-methyl tritiated trifluoperazine $(83 \mathrm{Ci} / \mathrm{mmol})$ used in the radioimmunoassay (RIA) for FLU, and side chain $\mathrm{N}^{4^{\prime}}$ methyl tritiated 7-hydroxy-trifluoperazine $(80 \mathrm{Ci} / \mathrm{mmol}$, 7-hydroxy functional group was protected with tetrahydropyranyl group) used in the RIA of 7-OH-FLU (Aravagiri et al. 1994a) were custom made by Amersham Corporation (Arlington Heights, IL). The radiolabeled sulfoxide and $\mathrm{N}^{4}$-oxide derivatives were made from tritiated trifluoperazine by oxidative chemical reactions, purified by liquid chromatography (Aravagiri et al. 1984, 1990), and used in the RIA for FLU-SO (Midha et al. 1988) and FLU-NO (Aravagiri et al. 1990), respectively. The purity of radiolabeled trifluoperazine and its 7-hydroxy, sulfoxide, and $\mathrm{N}^{4^{\prime}}$-oxide derivatives as determined by thin-layer chromatography were greater than $95 \%$. Radioactivity was measured by liquid scintillation counting using Scintiverse scintillation cocktail (Fisher Scientific) in a Tricarb 1900 TR liquid scintillation counter (Packard Instrument Company, Downers Grove, IL) equipped with automatic quench compensation.

\section{Antibodies}

The antibodies used in the RIAs of FLU-SO, 7-OH-FLU, and FLU-NO were polyclonal antibodies raised against suitable trifluoperazine sulfoxide, trifluoperazine 7-hydroxy, and prochlorperazine $\mathrm{N}^{4^{\prime}}$-oxide hapten-BSA conjugate based immunogens in New Zealand white rabbits (Aravagiri et al. 1984, 1985, 1986) The antibody used in the RIA of FLU was monoclonal and raised against a FLU hapten-thyroglobulin-based immunogen using hybridoma technique in mice as reported previously (McKay et al. 1990).
Antisera used in this study were generated based on the principle that the carrier protein was covalently attached to the drug molecule at a position that is farthest away from that part of the molecule required to be recognized by the antibody. Thus the antisera generated with hapten-protein conjugate of one of the piperazinyl phenothiazine neuroleptics would be expected to cross-react with other congeners of piperazinyl phenothiazine neuroleptics but not with other aliphatic or piperidinyl phenothiazine neuroleptics. Similarly the antibody raised against the metabolite-hapten-protein conjugate would be expected to cross-react with the respective metabolite of congeners of piperazinyl phenothiazine neuroleptics. Thus, in accordance with the nature of hapten, the specificity of antibodies as assessed by the criteria of Abraham (1969) showed significant binding to corresponding piperazinyl phenothiazine congeners such as fluphenazine, prochlorperazine, trifluoperazine but not to aliphatic or piperidinyl phenothiazine neuroleptics (Table 1). For the same reason, the RIAs used in this study were developed using radiolabeled trifluoperazine and its metabolites as tracers. Furthermore, the preparation of radiolabeled metabolites of FLU from tritiated FLU was not economically feasible.

Because the assay is only applicable under conditions where a single piperazinyl phenothiazine neuroleptic is used and not where more than one or unknown piperazinyl phenothiazine neuroleptics is used, specificity was also examined by a method closely resembling the clinical situation. In this method the specificity was examined by comparing values for samples spiked with each specific analyte over the range of the standard curve in the presence or absence of a five-fold excess of either FLU or its metabolites. Such additions did not result in significant changes in the values obtained for the specific analyte being assayed (t-test, $p<.05, n=5$ ).

\section{Animal Treatment}

Young male Sprague-Dawley albino rats (100 g) were purchased from Harlen Sprague Dawley (San Diego, CA). After being quarantined for 1 week, animals were housed (five to 10 per cage with free access to food and water in a temperature-regulated room $\left(23^{\circ} \mathrm{C}\right.$ to $\left.25^{\circ} \mathrm{C}\right)$ with a 12-hour lighting cycle (on 0600 to 1800 hours). They were gently handled daily for another week to prepare them for the study. All animal experimental procedures were approved by the West Los Angeles VAMC or McLean Hospital Animal Research Committees.

Rats were given the following daily doses of FLU dihydrochloride in aqueous solution once daily by oral gavage for 15 consecutive days (at 0900 to 1100 hours): $5(n=8), 10(n=15)$ or $20(n=10) \mathrm{mg} / \mathrm{kg}$. Higher doses produced weight loss and were not used. Six hours af- 
Table 1. Cross-Reactions ${ }^{a}$ of the Antiserum Used in the RIA of FLU, FLU-SO, 7-OH-FLU, and FLU-NO

\begin{tabular}{|c|c|c|c|c|}
\hline \multirow[b]{2}{*}{ Compound Tested } & \multicolumn{4}{|c|}{ Antibody Used in the RIA of } \\
\hline & FLU & FLU-SO & 7-OH-FLU & FLU-NO \\
\hline FLU & 100 & $<1$ & $<1$ & 1 \\
\hline FLU-SO & 4 & 100 & $<1$ & $<1$ \\
\hline 7-OH-FLU & 62 & $<1$ & 100 & $<1$ \\
\hline FLU-NO & 5 & 1 & $<1$ & 100 \\
\hline N-DeshydroxyethylFLU & 5 & 1 & $<1$ & 2 \\
\hline N-DeshydroxyethylFLU-SO & & 62 & $<1$ & $<1$ \\
\hline 7-Hydroxy-N-deshydroxyethylFLU & & 1 & $<1$ & \\
\hline Trifluoperazine & & & & 1 \\
\hline Trifluoperazine sulfoxide & & 56 & & \\
\hline 7-Hydroxytrifluoperazine & & & 83 & \\
\hline Trifluoperazine $\mathrm{N}^{4 \prime}$-oxide & & & & 100 \\
\hline Prochlorperazine $\mathrm{N}^{4 \prime}$-oxide & & & & 100 \\
\hline Chlorpromazine $\mathrm{N}$-oxide & & & & 1 \\
\hline Prochlorperazine sulfoxide & & 67 & & \\
\hline 7-Hydroxychlorpromazine & & & $<1$ & \\
\hline
\end{tabular}

ter the last daily dose, animals were decapitated. The 6-hour sampling time was derived from pilot data as the time at which the concentration of FLU was between peak and trough concentration in plasma (Aravagiri et al. 1994b). Upon decapitation, trunk blood was collected in heparinized tubes, and liver, kidney, and abdominal fat were removed and quickly frozen in dry ice. Whole brains from four to seven rats in each treatment group were removed and similarly frozen. Other brains were removed and quickly dissected over ice, into cerebellum, frontoparietal cortex, corpus striatum, midbrain (pons medulla), hypothalamus, hippocampus, and the remainder (rest of the brain), and rapidly frozen on dry ice. Blood was centrifuged at $4^{\circ} \mathrm{C}$ for 10 minutes at 1,725 $\times g$, and plasma removed. All samples were stored at $-60^{\circ} \mathrm{C}$ until assayed. To minimize experimental variations, all drug administration was performed by one investigator, and tissue dissections were carried out by another investigator. Coefficients of variation in the weight of brain tissue samples were less than $\pm 20 \%$.

All tissues were homogenized in $10 \mathrm{ml}$ of ice-cold physiologic saline $(150 \mathrm{mM} \mathrm{NaCl})$. Suitably diluted aliquots of these homogenates were assayed for FLU, FLU-SO, 7-OH-FLU, and FLU-NO by sensitive and specific RIAs (Aravagiri et al. 1990, 1994a; Midha et al. 1988; McKay et al. 1990). The lower limit of determination for all RIAs was $0.1 \mathrm{ng}$ of analyte/ml.

\section{Extraction of FLU and Its Metabolites}

FLU was extracted from an $0.8 \mathrm{ml}$ aliquot of suitably diluted homogenate after alkalinization with $0.1 \mathrm{ml}$ of saturated sodium carbonate ( $\mathrm{pH}$ ca. 10 ) using $7 \mathrm{ml}$ of $5 \%(\mathrm{vol})$ isopropanol in pentane. 7-OH-FLU was extracted from alkalinized samples $(0.1 \mathrm{ml}$ of saturated sodium carbonate added to $0.8 \mathrm{ml}$ of homogenate) by a two-step extraction procedure (Aravagiri et al. 1994a), first washing with $7 \mathrm{ml} \mathrm{n}$-pentane by shaking for 10 minutes and centrifuging at $18^{\circ} \mathrm{C}$ for 10 minutes at $1,725 \times g$, and then extracting into $7 \mathrm{ml}$ of diethylether. FLU-SO was extracted from similarly alkalinized samples $(0.8 \mathrm{ml})$ into $7 \mathrm{ml}$ of a mixture of dichloromethane and ether (20:80, vols). FLU-NO was extracted by a twostep procedure, first washing the alkalinized samples with $7 \mathrm{ml}$ of diethylether by shaking for 10 minutes and centrifuging at $18^{\circ} \mathrm{C}$ for 10 minutes at $1,725 \times g$, and then extracting into $7 \mathrm{ml}$ of a mixture of ethyl acetate, dichloromethane and isopropanol (75:20:5, vols; Aravagiri et al. 1990). The extracts were evaporated to dryness at $55^{\circ} \mathrm{C}$ under a stream of nitrogen. The residues were dissolved in $7 \%(\mathrm{w} / \mathrm{v})$ aqueous bovine serum albumin (BSA) and subsequently assayed for FLU, FLU-SO, FLU-NO, or 7-OH-FLU by RIA. Recovery of FLU and its metabolites was determined by comparing the concentration values for spiked standards obtained by their respective RIAs before and after their respective extraction procedure. The average percentage recovery of FLU, FLU-SO, FLU-NO, and 7-OHFLU, respectively, over the standard curve range of 0.1 to $10 \mathrm{ng} / \mathrm{ml}$ was ca. $86 \%, 72 \%, 65 \%$, and $61 \%$ of the spiked amount.

Individual antibody characterization and RIA procedures are detailed elsewhere (Midha et al. 1988; McKay et al. 1990; Aravagiri et al. 1990, 1994a). Sample extracts were assayed in triplicates in subdued light. An aliquot of reconstituted sample extract in BSA (200 $\mu \mathrm{l})$ was taken into $12 \times 75 \mathrm{~mm}$ polystyrene tubes to which $250 \mu$ l of tritiated tracer solution containing approximately $33,000 \mathrm{dpm}(15 \mathrm{nCi})$ was added. After shaking the tubes for 5 seconds, $250 \mu$ l of working antibody 
solution was added. All these additions were carried out in an ice bath. The tubes were shaken for 5 seconds and incubated in a water bath at $37^{\circ} \mathrm{C}$ for 75 to 90 minutes. Tubes were then cooled in an ice bath for 5 minutes. One $\mathrm{ml}$ of dextran-coated charcoal was added to each tube, mixed for 5 seconds, incubated for 30 minutes at $4^{\circ} \mathrm{C}$ in a refrigerator, and subsequently centrifuged for 12 minutes at $4^{\circ} \mathrm{C}$ at $1,725 \times \mathrm{g}$. Clear supernatant liquid from each tube was decanted into a plastic vial containing $8 \mathrm{ml}$ of scintillation fluid, mixed well and counted for 5 minutes in a 1900 TR scintillation counter.

The between-days and within-day variations were determined with spiked saline standards and tissue samples. The between-day assay variations were calculated from determined concentrations of the spiked standards and tissue samples analyzed on different days $(n=5)$. The within-day assay variations were calculated from the determined concentration of similarly spiked quality control samples and tissue samples analyzed on a single day $(n=5)$. The coefficients of variation in both instances were less than $15 \%$ for the spiked standards and the tissues samples examined.

\section{Dopamine Receptor Affinity}

Dopamine receptor affinities of FLU and its metabolites were determined with homogenates of corpus striatum tissue from the forebrain of young adult SpragueDawley rats (Charles River Labs., Wilmington, MA), prepared as reported previously (Baldessarini et al. 1992). Radioligands (DuPont-NEN, Boston, MA) were ${ }^{3} \mathrm{H}-\mathrm{SCH}-23390$ for $\mathrm{D}_{1}(85 \mathrm{Ci} / \mathrm{mmol} ; \mathrm{C}=300 \mathrm{pM})$ and ${ }^{3} \mathrm{H}$-emonapride $\left({ }^{3} \mathrm{H}-[ \pm]-Y M-09151-2 ; 85 \mathrm{Ci} / \mathrm{mmol} ; \mathrm{C}=\right.$ $65 \mathrm{pM}$ ) for $\mathrm{D}_{2}$ receptors. Specific binding was defined with $300 \mathrm{nM}$ cis-flupenthixol ( $\mathrm{D}_{1}$ assay; generously donated by Lundbeck Labs., Copenhagen, Denmark) or $200 \mathrm{nM}$ [+]butaclamol ( $\mathrm{D}_{2}$ assay; RBI, Natick, MA). Assay conditions are detailed elsewhere (Faedda et al. 1989; Baldessarini et al. 1992; Kula et al. 1992). At least six concentrations of each test compound were included with two to four replicates, and values for in vitro affinity as $\mathrm{IC}_{50}+\mathrm{SE}(\mathrm{nM})$ were determined by computer using the ALLFIT program for the MacIntosh microcomputer (DeLean et al. 1978; Teicher 1983; program generously donated by Dr. P.J. Munson of the $\mathrm{NIH})$. The results converted to values of $\mathrm{K}_{\mathrm{i}}=\mathrm{IC}_{50} /[1$ $\left.+\left(K_{d} / C\right)\right]$, according to Cheng and Prusoff (1973). Statistical computations were carried out using SAS and BMDP programs for the IBM200 $\mu 1$ of microcomputer.

\section{RESULTS}

Mean tissue levels of FLU, FLU-SO, FLU-NO, and 7-OH-FLU after 2 weeks of treatment with FLU dihydrochloride are summarized in Figure 2, with representative tissue levels after the $5 \mathrm{mg} / \mathrm{kg}$ daily dose given in Table 2. Mean ratios of tissue to plasma levels of FLU and its metabolites are shown in Figure 3, and the mean ratios of metabolite to FLU levels are shown in Figure 4. The relationship between plasma and regional brain FLU levels is given in Figure 5.

At all doses of FLU, levels of FLU and its three metabolites were quantifiable in all brain regions (Table 2 , Figure 2). The concentrations of FLU and FLU-SO were relatively high, whereas those of 7-OH-FLU and FLU-NO were much lower and near the lower limit of determinations. In all tissues, levels of all four compounds increased with daily doses ranging from $5 \mathrm{mg}$ to $20 \mathrm{mg}$ (Figure 2). In brain tissues, FLU levels doubled as the daily dose of FLU increased from 5 to 10 $\mathrm{mg} / \mathrm{kg}$ but quadrupled when the dose was increased from 10 to $20 \mathrm{mg} / \mathrm{kg}$. The FLU level (ng/g) in brain tissues normalized per $\mathrm{mg} / \mathrm{kg}$ of administered dose averaged 341,423 , and $693 \mathrm{ng} / \mathrm{g}$ for doses of $5,10,20 \mathrm{mg} / \mathrm{kg}$ of FLU, respectively. The sulfoxide was the major metabolite present at significant levels in all tissues analyzed; in brain, it ranged from $24 \%$ to $96 \%$ those of FLU (Figure 3).

Concentrations of FLU and its three metabolites in brain tissues increased with daily dose but the slopes of the regression equation relating concentration and dose (change in accumulation) varied with compound and brain region. For example, the change in the accumulation of FLU with dose was nearly twice as great in cortex and hippocampus as in cerebellum or hypothalamus. On the other hand, cortex and hypothalamus accumulated FLU-SO and FLU-NO equally but the accumulation of 7-OH-FLU in hypothalamus and hippocampus was only half that in cortex. In general, the change in accumulation of FLU and its metabolites followed the order of their tissue concentrations (average spearman rank correlation $\mathrm{r}_{\mathrm{s}}=0.76, p<.005$ ).

In brain, there were only small, nonsignificant, differences in the levels of FLU and its metabolites among anatomic regions (usually less than two-fold). For example, the concentrations of FLU were high in the cortex and the rest of the brain at all doses, and the concentrations of FLU-SO and FLU-NO were highest in the hypothalamus (Figure 2). The concentrations of FLU-SO and 7-OH-FLU in midbrain were relatively low.

The concentrations of FLU and FLU-SO were 10 to 58 times higher in various brain regions than in plasma, whereas concentrations of 7-OH-FLU and FLU-NO were relatively low (Figure 3). Brain and plasma levels of FLU were significantly correlated with some variation between brain regions (Figure 5). The linear correlation of tissue to plasma FLU level was strongest for caudate, cortex, and hippocampus $(\mathrm{r}=0.83,0.68$, and 0.70 , respectively, $p<.005$ ), and somewhat weaker for hypothalamus $(\mathrm{r}=0.67 ; p=.02)$ and cerebellum and midbrain (average $\mathrm{r}=0.60 ; p=.02$ ) (Figure 5). There were no significant correlations between plasma and brain levels of FLU-SO for any brain region. Correla- 

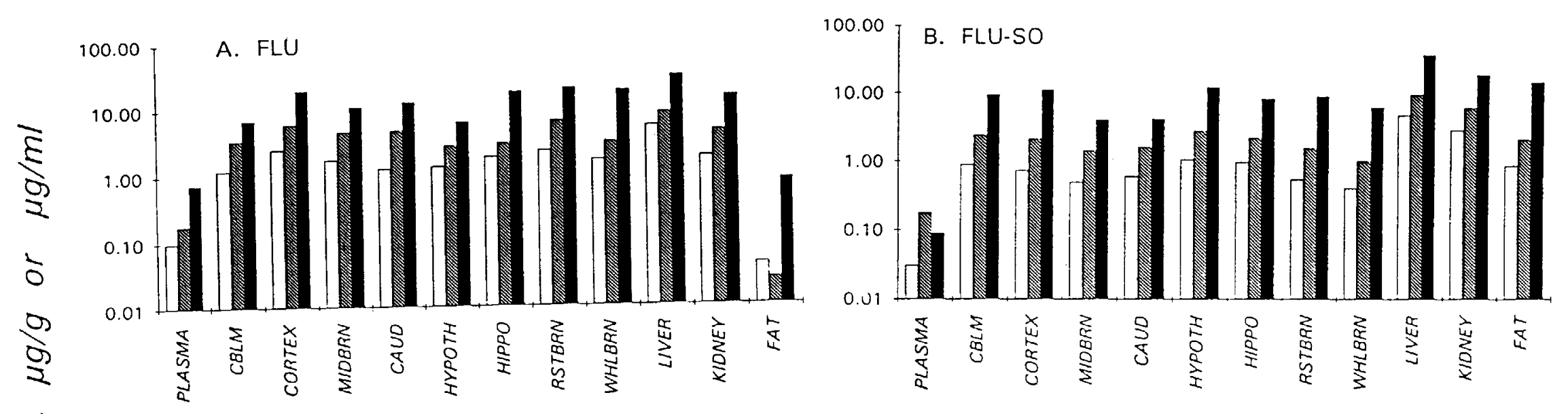

$\frac{2}{2}$

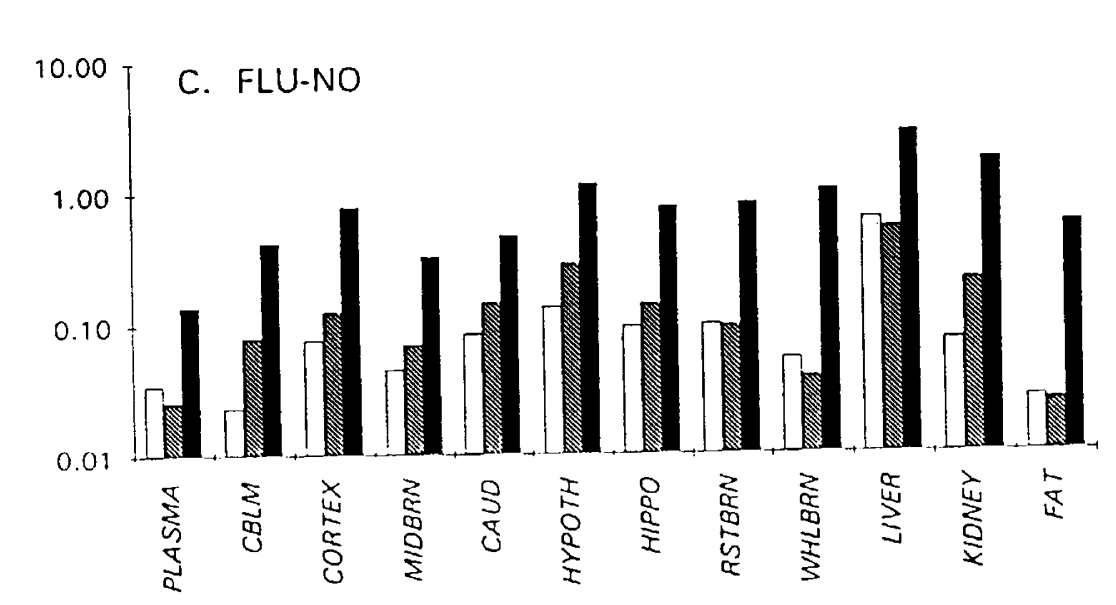

1.000 D. 7-OH-FLU

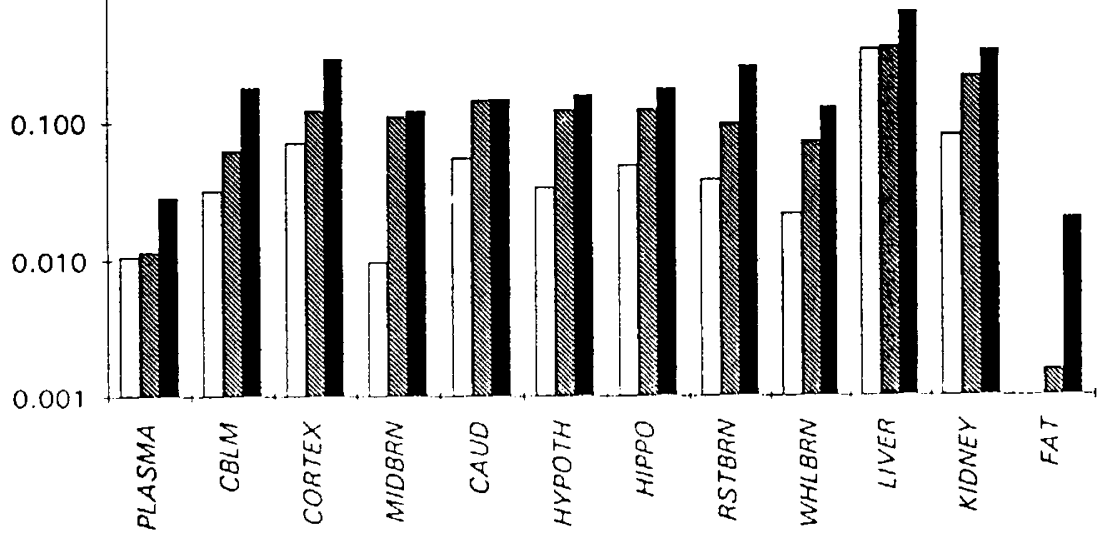

Figure 2. Mean concentrations of FLU, FLU-SO, FLU-NO and 7-OH-FLU in plasma, peripheral tissues, and in regions of rat brain 6 hours after the last daily oral doses of 5 (open bars), 10 (hatched bars), or 20 (solid bars) $\mathrm{mg} / \mathrm{kg}$ of FLU dihydrochloride administered for 15 days. The relationship between daily FLU dose and the analytes levels in brain regions showed moderate to high correlation $\left(\mathrm{r}_{\mathrm{s}}=0.56\right.$ to $\left.0.93 ; p \leqslant .008\right)$ for FLU, FLU-SO, FLU-NO, and 7-OH-FLU. FLU levels in brain:plasma were correlated $\left(r_{\mathrm{s}}=0.73\right)$, but the brain:plasma correlation was poor for the metabolites $\left(\mathrm{r}_{\mathrm{s}}=0.1\right.$ to 0.88$)$. 
Table 2. Mean \pm SD of Concentrations (ng/g or $\mathrm{ng} / \mathrm{ml}$ ) of Fluphenazine and Its Metabolites in Brain and Peripheral Tissues at 6 Hours after the Last of 15 Daily Oral Doses of Fluphenazine Hydrochloride $(5 \mathrm{mg} / \mathrm{kg}$ )

\begin{tabular}{lcccc}
\hline \multicolumn{1}{c}{ Tissue } & \multicolumn{1}{c}{$\begin{array}{c}\text { FLU } \\
(\boldsymbol{n} / \mathbf{g})\end{array}$} & $\begin{array}{c}\text { FLU-SO } \\
(\boldsymbol{n g} / \boldsymbol{g})\end{array}$ & $\begin{array}{c}\text { FLU-NO } \\
(\boldsymbol{n g} / \boldsymbol{g})\end{array}$ & $\begin{array}{c}\text { 7-OH-FLU } \\
(\boldsymbol{n g} / \mathbf{g})\end{array}$ \\
\hline Whole brain & $1611 \pm 388$ & $\mathbf{4 0 4} \pm 101$ & $54.4 \pm 21.2$ & $22.1 \pm 6.7$ \\
Cerebellum & $1193 \pm 617$ & $890 \pm 474$ & $23.5 \pm 19.8$ & $32.3 \pm 7.8$ \\
Cortex & $2473 \pm 579$ & $732 \pm 340$ & $76.6 \pm 30.0$ & $71.7 \pm 17.7$ \\
Midbrain & $1701 \pm 777$ & $494 \pm 210$ & $46.1 \pm 15.6$ & $9.6 \pm 5.2$ \\
Caudate & $1251 \pm 1078$ & $598 \pm 262$ & $84.7 \pm 18.0$ & $56.4 \pm 13.6$ \\
Hypothalamus & $1315 \pm 504$ & $1060 \pm 355$ & $135.1 \pm 52.1$ & $34.4 \pm 21.6$ \\
Hippocampus & $1828 \pm 585$ & $980 \pm 313$ & $96.0 \pm 42.3$ & $50.0 \pm 10.6$ \\
Rest of brain & $2256 \pm 447$ & $547 \pm 220$ & $99.1 \pm 43.9$ & $39.2 \pm 16.7$ \\
Plasma* & $98 \pm 53$ & $31 \pm 8$ & $35.2 \pm 16.3$ & $10.6 \pm 3.8$ \\
Liver & $5257 \pm 1449$ & $4690 \pm 1756$ & $628 \pm 229$ & $339 \pm 72$ \\
Kidney & $1750 \pm 726$ & $2831 \pm 982$ & $74.7 \pm 32.3$ & $82.8 \pm 30.2$ \\
Fat & $42 \pm 81$ & $859 \pm 809$ & $27.1 \pm 15.1$ & $0.9 \pm 0.4$ \\
\hline
\end{tabular}

For brain, $n=4$, for peripheral tissues, $n=8$. Abbreviations: FLU, fluphenazine; FLU-SO, fluphenazine sulfoxide; FLU-NO, fluphenazine $\mathrm{N}^{4}$-oxide; 7-OH-FLU, 7-hydroxy-fluphenzine.

${ }^{*}$ Plasma the only tissue measured by $\mathrm{ng} / \mathrm{ml}$.

tions between plasma and brain levels of 7-OH-FLU were significant only for caudate, cerebellum, cortex, and whole brain (average $\mathrm{r}=0.60 ; p=.05$ ). For FLU$\mathrm{NO}$, the plasma and brain levels were significantly related only with respect to caudate, hippocampus and midbrain $(\mathrm{r}=0.65$ to $0.80 ; p \leqslant .02)$.

The levels of FLU and its metabolites in liver, kidney, and abdominal fat also increased with the administered dose of FLU. The concentrations of all four compounds were highest in the liver at 6 hours after the last of all three daily doses. As in brain, the concentrations of FLU-NO and 7-OH-FLU in liver were lower than those of FLU and FLU-SO, whereas FLU and FLU. $\mathrm{SO}$ were present in about equal concentrations in liver and kidney. FLU-NO and 7-OH-FLU concentrations in liver and kidney were similar except for the highest daily dose of FLU $(20 \mathrm{mg} / \mathrm{kg})$, after which FLU-NO was nearly five-fold higher than 7-OH-FLU in both organs.

The pattern of concentrations of metabolites in abdominal fat differed from that of most other tissues. Although FLU is relatively nonpolar at physiologic $\mathrm{pH}$ (pKa 3.9, 8.1; Florey 1973), FLU concentrations in fat after daily oral doses of 5 and $10 \mathrm{mg} / \mathrm{kg}$ were below its plasma concentrations and similar to plasma levels after $20 \mathrm{mg} / \mathrm{kg}$. In contrast, fat FLU-SO levels were $43-$ to 75 -fold higher than FLU levels in fat (Figure 4), and 11 to 157 times above the plasma level (Figure 3). This pattern may reflect the low polarity of FLU-SO and a consequent tendency to accumulate in fat tissue. On the other hand, concentrations of FLU-NO in fat were similar to plasma levels except at the $20 \mathrm{mg} / \mathrm{kg}$ dose, whereas concentrations of 7-OH-FLU were much lower in fat than in plasma, averaging only $10 \%$ of plasma levels at daily doses of 5 and $10 \mathrm{mg} / \mathrm{kg}$. A significant correlation between tissue and plasma levels was observed for FLU and 7-OH-FLU in liver and kidney ( $\mathrm{r}=$
0.6 to $0.7, p \leqslant .005)$. A similar correlation was observed for FLU-SO in kidney only, and no significant correlation was found for FLU-NO in these peripheral tissues.

The binding competition of FLU metabolites at striatal dopamine receptors (Table 3 ) showed that FLU-SO and FLU-NO had only $1 \%$ to $3 \%$ the affinity of FLU for $D_{1}$ and $D_{2}$ receptors, but 7-OH-FLU had $20 \%$ of the $D_{2}$, and $5 \%$ the $D_{1}$ affinity of FLU.

\section{DISCUSSION}

FLU and its metabolites were found in quantifiable amounts in all of the rat brain regions evaluated in this study. In these same areas FLU-SO was the major metabolite. Whereas concentrations of FLU and its metabolites varied widely in peripheral tissues, there were only minor regional differences in brain and no indication of preferential localization. The present data can not determine whether the FLU metabolites in brain were formed in situ and/or were formed in peripheral tissues and reached the brain by blood circulation, or both.

Since plasma levels are widely used to predict clinical response and guide therapeutic interventions, the relationship between brain and plasma levels of FLU and its metabolites, and the extent to which neuropharmacologic effects of FLU might reflect contributions of its metabolites are of considerable importance. Although the studies described here are in rat, extrapolation to humans should be considered with caution. The correlations between plasma and tissue concentrations were strongest for FLU in cortex but also substantial for concentrations in caudate and hippocampus, as well as in whole brain (Figure 5). There were some regional variations in brain, with FLU concentrations being highest in cortex and twice its concentration in caudate. 


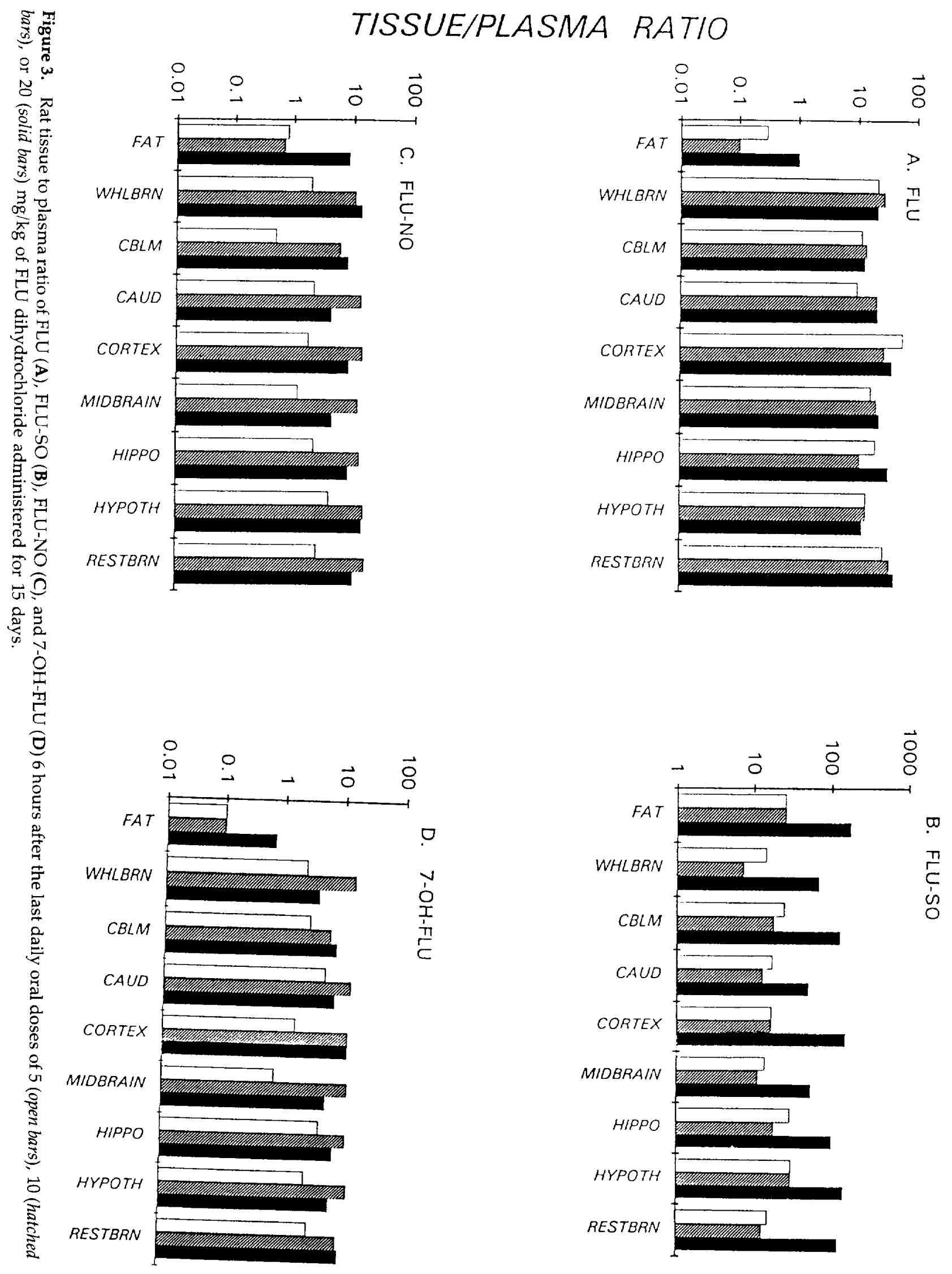



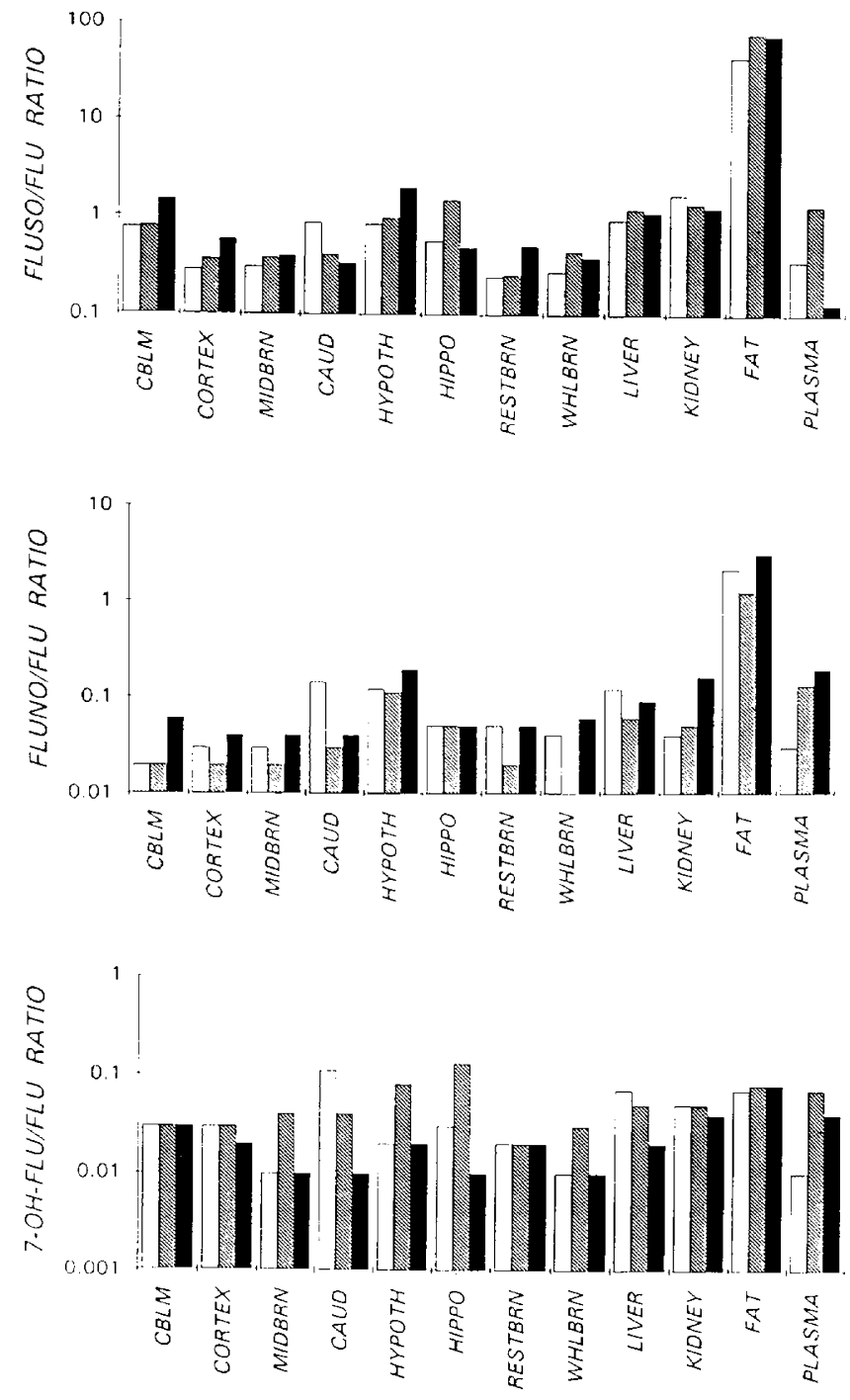

Figure 4. Ratio of FLU-SO, FLU-NO, and 7-OH-FLU to FLU in brain tissues and fat, 6 hours after the last daily oral doses of 5 (open bars), 10 (hatched bars), or 20 (solid bars) $\mathrm{mg} / \mathrm{kg}$ of FLU dihydrochloride administered for 15 days. FLU-SO was a major metabolite found in all tissues at all dose levels. FLUSO metabolite seems to accumulate in fat (43- to 75-fold higher than FLU).

The significance of these minor regional variations in drug distribution in brain to the therapeutic and extrapyramidal side-effects of FLU is unclear.

Among the three metabolites analyzed, concentrations of FLU-SO in brain tissues were highest at all doses, ranging from $24 \%$ to $96 \%$ those of FLU. Despite its relatively high concentrations in brain, the possibility of an important neuropharmacologic contribution of FLU-SO is unlikely, as it had 170 times less affinity than FLU for $D_{2}$ receptors and 300 times less affinity at $D_{1}$ receptors.

Of the other metabolites, the plasma levels of 7-OH-
FLU correlated significantly with its concentrations in caudate, cerebellum, cortex, and whole brain, but to a lesser extent in hippocampus, hypothalamus, or midbrain. Whereas 7-OH-FLU had moderate affinity for the $\mathrm{D}_{2}$ receptors, about $20 \%$ that of FLU, its concentration in brain was only about $1 \%$ to $7 \%$ of that of FLU. Therefore, the contribution of 7-OH-FLU to the clinical effects of FLU is also likely to be insignificant.

Correlations between FLU-NO concentrations in plasma and brain regions varied widely. Plasma concentrations of FLU-NO correlated significantly with its concentrations in caudate, cortex, hippocampus, midbrain, and whole brain but not those in cerebellum or hypothalamus. The presence of the FLU-NO metabolite in brain may be important because of its reported moderate $\mathrm{D}_{2}$ intrinsic antidopaminergic activity $\left(\mathrm{K}_{\mathrm{i}}=\right.$ $82 \mathrm{nM}$ vs [ $\left.{ }^{3} \mathrm{H}\right]$ spiperone in Lewis et al. (1983) and $5 \mathrm{nM}$ vs $\left[{ }^{3} \mathrm{H}\right]$ emanopride (in this study) and its possible connection to disabling side-effects (Van Putten et al. 1991). Also FLU-NO may be metabolically converted back to FLU in brain (unpublished observation with rat brain homogenate) and in liver (Lewis et al. 1983). Similar metabolic reconversions of metabolites to parent compounds have been reported. For example, chlorpromazine $\mathrm{N}$-oxide can be reduced to chlorpromazine (Jaworski et al. 1990; Lewis et al. 1983), clozapine $\mathrm{N}$-oxide to clozapine (Lin et al. 1995) and hydroxy-haloperidol can be oxidized back to the ketone haloperidol (Korpi et al. 1985; Chakraborty et al. 1989; Jann et al. 1990). Such a reconversion of FLU-NO to FLU may contribute to the overall pharmacologic actions of FLU. Despite this, the low concentrations of FLU-NO encountered in brain, about $3 \%$ of FLU (Tables 1 and 2), indicates that the contribution to the neuropharmacologic effect of FLU by FLU-NO itself is likely to be negligible.

The relative neuropharmacologic activity of neuroleptics is presumed to correlate with the relative concentration of the drug at active sites in the brain and their $\mathrm{D}_{2}$ receptor affinity. Thus a relative "activity factor" was estimated for FLU, FLU-SO, 7-OH-FLU and FLU-NO as the product of their relative abundance and relative $D_{2}$ receptor affinity with respect to FLU (Table 4). The data indicated that FLU is the primary compound responsible for its neuropharmacologic actions, and the contribution by metabolites is negligible. Among the metabolites, FLU-SO seems to be the major contributor to the total neuroleptic activity with less than $1 \%$ of the activity of FLU. Although 7-OH-FLU was the most potent of the three metabolites studied here, its contribution to overall neuroleptic activity is less than $0.5 \%$ of FLU due to its low concentration in brain and the contribution of FLU-NO metabolite is least among the three metabolites.

The findings from this study indicating that tissue levels of FLU and its metabolites greatly exceeded plasma levels is of some interest. In a pilot pharmaco- 


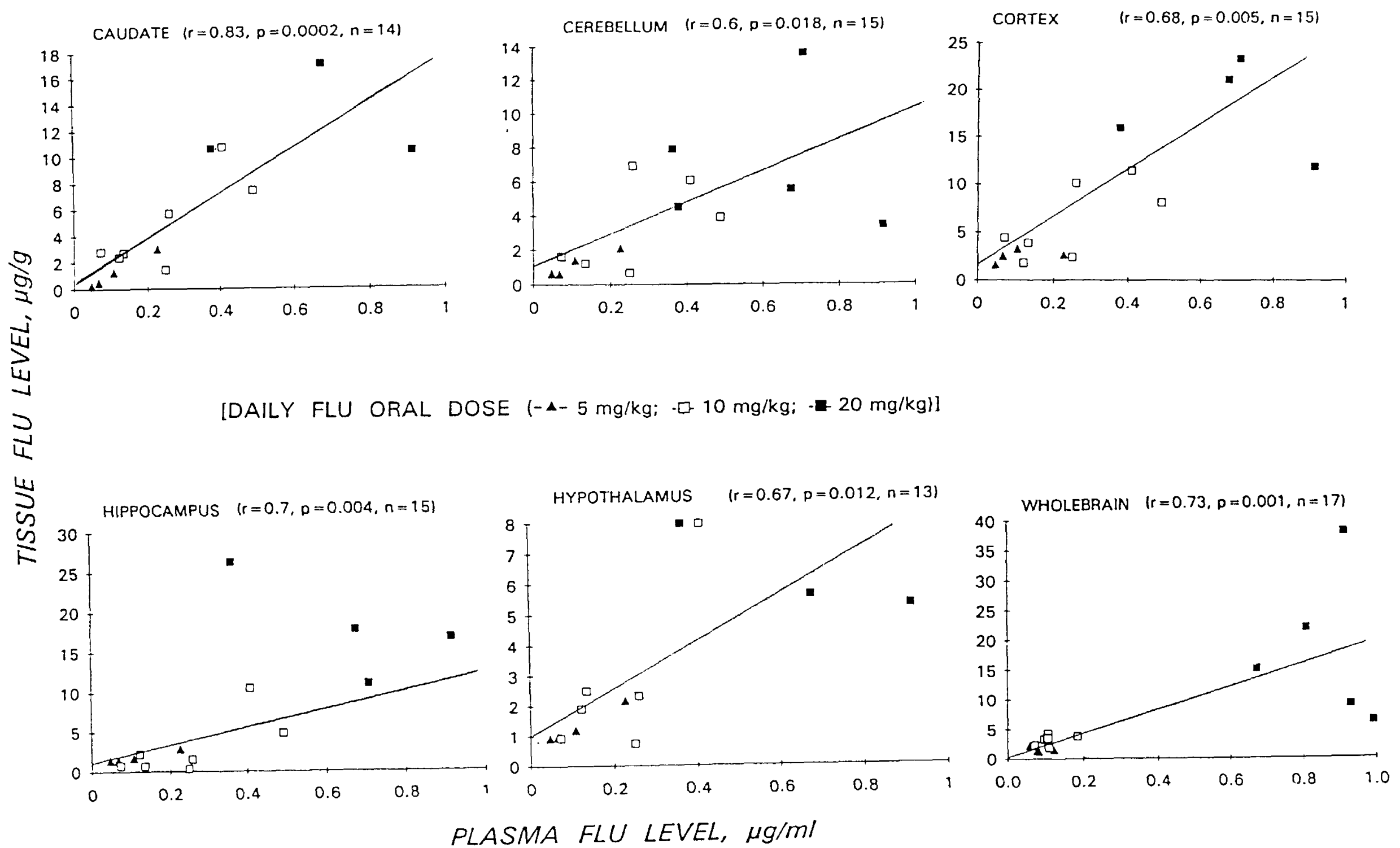

Figure 5. Scatter plot of concentrations of FLU in plasma and in various regions of rat brain 6 hours after the last daily oral doses of 5, 10, or $20 \mathrm{mg} / \mathrm{kg}$ of FLU dihydrochloride administered for 15 days. 
Table 3. Dopamine Receptor Affinities of Fluphenazine and Its Metabolites

\begin{tabular}{|c|c|c|c|}
\hline \multirow[b]{2}{*}{ Ratio } & \multicolumn{2}{|c|}{$K_{i}(n M) \pm S E$} & \multirow{2}{*}{$\begin{array}{c}\mathrm{D}_{2} \text { vs. } \mathrm{D}_{1} \\
\text { Potency }\end{array}$} \\
\hline & $\mathbf{D}_{1}$ & $\mathbf{D}_{2}$ & \\
\hline FLU & $1.22 \pm 0.17$ & $0.12 \pm 0.01$ & 10.1 \\
\hline FLU-SO & $340 \pm 44$ & $21.7 \pm 2.70$ & 15.7 \\
\hline 7-OH-FLU & $31.3 \pm 3.5$ & $0.68 \pm 0.07$ & 46 \\
\hline FLU-NO & $280 \pm 37$ & $4.67 \pm 0.63$ & 60 \\
\hline 7-OH-FLU-glucuronide & ca. 5,000 & $37.4 \pm 10.7$ & ca. 1,337 \\
\hline
\end{tabular}

$\mathrm{D}_{1}$ affinity was assayed with ${ }^{3} \mathrm{H}-\mathrm{SCH}-23390(\mathrm{C}=300 \mathrm{pM}$, blank $=300 \mathrm{nM}$ cis-flupenthixol, $30 \mathrm{~min}$ at $\left.30{ }^{\circ} \mathrm{C}\right) ; \mathrm{D}_{2}$ was assayed with ${ }^{3} \mathrm{H}$-emonapride $(\mathrm{C}=65 \mathrm{pM}$, blank $=200 \mathrm{nM}[+]$ butaclamol, $90 \mathrm{~min}$ at $30^{\circ} \mathrm{C}$ ). Assay data were obtained with at least six concentrations at each test agent, in two to four replicates, and then computer-fit by the ALLFIT program to obtain $\mathrm{IC}_{50} \pm \mathrm{SEM}$, which was converted to $\mathrm{K}_{\mathrm{i}}=\mathrm{IC}_{50} /\left[1+\left(\mathrm{K}_{\mathrm{d}} / \mathrm{C}\right)\right]$. Abbreviations: FLU, fluphenazine, FLU-SO, fluphenazine sulfoxide; FLU$\mathrm{NO}$, fluphenazine $\mathrm{N}_{4}$-oxide; 7-OH-FLU, 7-hydroxyfluphenazine; $\mathrm{C}$, concentration.

kinetics study (Aravagiri et al. 1994b), where a single oral dose of $10 \mathrm{mg}$ of FLU/ $\mathrm{kg}$ was administered to rats and the plasma and tissue levels of FLU and its metabolites were followed for 24 hours, the terminal elimination half-life ( $\left(t \frac{1}{2} \beta\right.$ calculated between 5 and 24 hours) of FLU and apparent $t 1 / 2 \beta$ of its metabolites in various brain regions were two to eight times longer than in plasma (Aravagiri et al. 1994b). Therefore, the higher brain levels as compared to plasma levels and the observed variations in the correlation between brain- and plasma-levels of FLU and its metabolites may be a function of accumulation, differences in their in situ metabolic formation, and entry into and elimination from brain regions.

The daily doses of FLU administered to rats $(10 \mathrm{mg}$ and $20 \mathrm{mg} / \mathrm{kg}$ ) in this study were much higher than clinical doses typically about 0.075 to $0.5 \mathrm{mg} / \mathrm{kg}$. At high doses, this type of nonlinearity between drug levels and doses has been reported previously in human subjects given a range of doses of intramuscular FLU (Denker et al. 1988), oral thioridazine (Axelsson 1974) or haloperidol (Forsman and Öhman 1974).

In summary, concentration of FLU and its metabolites in rat brain and other tissues were many-fold higher than in plasma after 2 weeks of oral administration of moderate to high daily dose of FLU dihydrochloride ( 5 to $20 \mathrm{mg} / \mathrm{kg}$ ). Levels of the 7-hydroxy and $\mathrm{N}^{4^{\prime}}$-oxide metabolites were much lower than those of FLU or FLU$\mathrm{SO}$ in brain and most other tissues including plasma. Variations in levels of FLU and its metabolites between brain regions were small, although cortex and caudate had somewhat higher levels than other regions. Tissue concentrations of FLU and its metabolites increased with increasing dosage of FLU, but nonlinearly at high doses, leading to higher levels in tissues than in plasma. Correlations between plasma and brain levels of FLU and its metabolites varied both with metabolite and brain region. Correlations were highest for FLU and FLU-NO, moderate for 7-OH- FLU, and lower for FLUSO. Substantial levels of FLU metabolites are found in

Table 4. Estimation of Relative "Activity Factor" in Brain for FLU, FLU-SO,

FLU-NO, and 7-OH-FLU

\begin{tabular}{|c|c|c|c|c|c|c|}
\hline $\begin{array}{l}\text { Daily } \\
\text { Dose }\end{array}$ & Compound & $\begin{array}{l}\text { Level } \\
(n g / g)\end{array}$ & $\begin{array}{c}\mathrm{D}_{2} \text { Receptor } \\
\text { Affinity }\end{array}$ & $\begin{array}{c}\text { Relative } \\
\text { Abundance }^{a}\end{array}$ & $\begin{array}{l}\text { Relative } \\
\text { Affinity }^{b}\end{array}$ & $\begin{array}{l}\text { "Activity } \\
\text { Factor"c } \\
\end{array}$ \\
\hline $5 \mathrm{mg} / \mathrm{kg}$ & $\begin{array}{l}\text { FLU } \\
\text { FLU-SO } \\
\text { FLU-NO } \\
\text { 7-OH-FLU }\end{array}$ & $\begin{array}{r}1611 \\
404 \\
54 \\
24\end{array}$ & $\begin{array}{c}0.12 \\
4.67 \\
21.7 \\
0.68\end{array}$ & $\begin{array}{l}1 \\
0.25 \\
0.033 \\
0.015\end{array}$ & $\begin{array}{l}1 \\
0.026 \\
0.005 \\
0.176\end{array}$ & $\begin{array}{r}1000 \\
6.44 \\
0.19 \\
2.63\end{array}$ \\
\hline $10 \mathrm{mg} / \mathrm{kg}$ & $\begin{array}{l}\text { FLU } \\
\text { FLU-SO } \\
\text { FLU-NO } \\
\text { 7-OH-FLU }\end{array}$ & $\begin{array}{r}3027 \\
1013 \\
40 \\
75\end{array}$ & $\begin{array}{c}0.12 \\
4.67 \\
21.7 \\
0.68\end{array}$ & $\begin{array}{l}1 \\
0.33 \\
0.013 \\
0.025\end{array}$ & $\begin{array}{l}1 \\
0.026 \\
0.005 \\
0.176\end{array}$ & $\begin{array}{l}1000 \\
8.6 \\
0.07 \\
4.37\end{array}$ \\
\hline $20 \mathrm{mg} / \mathrm{kg}$ & $\begin{array}{l}\text { FLU } \\
\text { FLU-SO } \\
\text { FLU-NO } \\
7-O H-F L U\end{array}$ & $\begin{array}{r}18118 \\
6298 \\
1029 \\
130\end{array}$ & $\begin{array}{c}0.12 \\
4.67 \\
21.7 \\
0.68\end{array}$ & $\begin{array}{l}1 \\
0.35 \\
0.06 \\
0.007\end{array}$ & $\begin{array}{l}1 \\
0.026 \\
0.005 \\
0.176\end{array}$ & $\begin{array}{r}1000 \\
8.93 \\
0.31 \\
1.27\end{array}$ \\
\hline
\end{tabular}

\footnotetext{
${ }^{a}$ Relative abundance is calculated as the ratio of concentration of compounds/FLU concentration.

${ }^{b}$ Relative affinity is calculated as the ratio of the reciprocal of $\mathrm{D}_{2}$ affinity of compounds/the reciprocal of FLU $D_{2}$ affinity.

"The relative "activity factor" is calculated as the product of relative abundance $\times$ relative $\mathrm{D}_{2}$ affinity $\times 1000$. In brain, FLU is $125,5,260$, and 360 times more potent than FLU-SO, FLU-NO, and 7-OHFLU, respectively.
} 
the plasma of schizophrenic patients treated with FLU (Marder et al. 1989). However, the low dopamine receptor affinity of FLU metabolites and low concentrations of 7-OH-FLU and FLU-NO encountered in various rat brain regions make it unlikely that these metabolites play a major role in clinical responses to treatment with FLU. Also, the estimated relative "activity factor" for FLU metabolites in brain indicate that the contribution to neuropharmacologic actions of FLU by its metabolites in rat is negligible and at best about $1 \%$ of that of FLU. Extrapolation of the findings from this animal study to clinical applications is risky (Janssen and Awouters 1994). Nevertheless, the present findings seem to suggest that plasma concentrations of FLU alone can provide useful information about the active drug substance in brain tissue.

\section{ACKNOWLEDGMENTS}

This study was supported by the University of California Los Angeles (UCLA) Mental Health Clinical Research Center for the Study of Schizophrenia (MH-30911), Department of Veterans Affairs Medical Research Service, and National Institute of Mental Health Grant MH-41573 (S.R. Marder). Also supported, in part by USPHS (NIMH) grants MH-31154, MH34006 , and MH-47370 and an award from the Bruce J. Anderson Foundation and the Vivian Tente Fund (R.J. Baldessarini) and Medical Research Council of Canada Program Grant MRCPG-11472 (K.K. Midha). The authors gratefully acknowledge the technical contributions of David Davidian, Psychopharmacology Unit, BVAMC, UCLA and Bennie Bennet, Neurobiochemistry Lab, BVAMC, UCLA.

\section{REFERENCES}

Abraham GE (1969): Solid phase radioimmunoassay of estradiol-17ß. J Clin Endocrinol 29:866-870

Alfredsson G, Wiesel FA, Skett P (1977): Levels of chlorpromazine and its active metabolites in rat brain and the relationship to central monoamine metabolism and prolactin secretion. Psychopharmacology 53:13-18

Aravagiri M, Hawes EM, Midha KK (1984): Radioimmunoassay for the sulfoxide metabolite of trifluoperazine and its application to a kinetic study in humans. J Pharm Sci $73: 1,383-1,387$.

Aravagiri M, Hawes EM, Midha KK (1985): Radioimmunoassay for the 7-hydroxy metabolite of trifluoperazine and its application to a kinetic study in human volunteers. J Pharm Sci 74:1,196-1,201.

Aravagiri M, Hawes EM, Midha KK (1986): Development and application of a specific radioimmunoassay for trifluoperazine $\mathrm{N}^{4^{\prime}}$-oxide to a kinetic study in humans. I Pharmacol Exp Ther 237:615-622

Aravagiri M, Marder SR, Van Putten T, Hawes EM, McKay G, Hubbard JW, Midha KK (1990): Therapeutic monitoring of steady-state plasma levels of the $\mathrm{N}^{4^{\prime}}$-oxide metabolite of fluphenazine in chronically treated schizo- phrenic patients determined by a specific and sensitive radioimmunoassay. Therapeutic Drug Monit 12:268-276

Aravagiri M, Marder SR, Van Putten T, Hawes EM, McKay G, and Midha KK (1994a): Radioimmunoassay for 7-hydroxy metabolite of fluphenazine and its application to plasma level monitoring in schizophrenic patients treated long term with oral and depot fluphenazine. Therapeutic Drug Monit 16:21-29

Aravagiri M, Marder SR, Yuwiler A (1994b): Pharmacokinetics of fluphenazine and its sulfoxide, 7-hydroxy and $\mathrm{N}^{4}$ oxide metabolites in various regions of rat brain after single oral dose of fluphenazine. Abstract; American Association of Pharmaceutical Scientists Annual Meeting, Nov 6-12, 1994; San Diego, California

Axelsson $R$ (1974): On the pharmacokinetics of thioridazine in psychiatric patients. In Sedvall G, Uvnäs B, Zotterman Y (eds), Antipsychotic Drugs: Pharmacodynamics and Pharmacokinetics. New York, Pergamon, pp 353-358

Baldessarini RJ, Cohen BM, Teicher MH (1988): Significance of neuroleptic dose and plasma level in pharmacologic treatment of psychoses. Arch Gen Psychiatry 45:79-91

Baldessarini RJ, Kula NS, Campbell A, Bakthavachalam V, Yuan J, Neumeyer JL (1992): Prolonged D 2 antidopaminergic activity of alkylating and nonalkylating derivatives of spiperone in rat brain. Mol Pharmacol 42:856-863

Baldessarini RJ, Centorrino F, Flood JG, Volpicelli SA, HustonLyons D, Cohen BM (1993): Tissue concentrations of clozapine and its metabolites in the rat. Neuropsychopharmacology 9:117-124

Breyer U, Gaertner HJ, Prox A (1974a): Formation of identical metabolites from piperazine and dimethylaminosubstituted phenothiazine drugs in man, rat, and dog. Biochem Pharmacol 23:313-322

Breyer U, Prox A, Bertele R, Gaertner HJ (1974b): Tissue metabolites of trifluoperazine, fluphenazine, prochlorperazine, and perphenazine in the rat: Identification and synthesis. J Pharm Sci 63:1,842-1,848

Chakraborty BS, Hubbard JW, Hawes EM, McKay G, Cooper JK, Gurnsey T, Korchinski ED, Midha KK (1989): Interconversion between haloperidol and reduced haloperidol in healthy volunteers. Eur J Clin Pharmacol 37:45-48

Cheng Y, Prusoff WH (1973): Relationship between the inhibition constant $\left(\mathrm{K}_{\mathrm{i}}\right)$ and the concentration of inhibitor which causes 50 percent inhibition $\left(\mathrm{IC}_{50}\right)$ of an enzymatic reaction. Biochem Pharmacol 22:3,099-3,108

Curry SH, Whelpton R, de Schepper PJ, Vranckx S, Schiff AA (1979): Kinetics of fluphenazine after fluphenazine dihydrochloride, enanthate, and decanoate administration to man. Br J Clin Pharmacol 7:325-331

Dahl, SG (1986): Plasma level monitoring of antipsychotic drugs. Clinical Pharmacokinet 11:36-61

DeLean A, Munson PI, Rodbard D (1978): Simultaneous analysis of families of sigmoid curves: Applications to bioassay, radio ligand, and physiologic dose-response curves. Am J Physiol 4:E97-E102

Dencker SJ, Johansson R, Malm U (1988): Pharmacokinetics and pharmacodynamic studies on high doses of fluphenazine. Psychopharmacology 94:237-241

Dreyfuss J, Cohen AI (1971): Identification of 7-hydroxy-fluphenazine as major metabolite of fluphenazine $-{ }^{14} \mathrm{C}$ in the dog. J Pharm Sci 60:826-828. 
Dreyfuss J, Ross JJ Jr, Schreiber EC (1971): Biologic disposition and metabolic fate of fluphenazine ${ }^{14} \mathrm{C}$ in the dog and rhesus monkey. J Pharm Sci 60:821-825.

Ebert AG, Hess SM (1965): The distribution and metabolism of fluphenazine enanthate. J Pharmacol Exp Ther 148: 412-421

Faedda G, Kula NS, Baldessarini RJ (1989): Pharmacology of binding ${ }^{3} \mathrm{H}-\mathrm{SCH}-23390$, a ligand selective for $\mathrm{D}_{1}$ dopamine receptor sites, in rat brain tissue. Biochem Pharmacol 38:473-480

Florey K (1973): Fluphenazine enanthate. In Florey K (ed), Analytical Profiles of Drug Substances, Vol. 2. New York, Academic Press, pp 254

Forsman A, Öhman R (1974): Some aspects of the distribution and metabolism of haloperidol in man. In Sedvall G, Uvnäs B, Zotterman Y (eds), Antipsychotic Drugs: Pharmacodynamics and Pharmacokinetics. New York, Pergamon, pp 359-365

Gaertner HJ, Breyer U, Liomin G (1974): Metabolism of trifluoperazine, fluphenazine, prochlorperazine, and perphenazine in rats: In vitro urinary metabolites. Biochem Pharmacol 23:303-311

Gaertner HJ, Liomin G, Villumsen D, Bertele R, Breyer U (1975): Tissue metabolites of trifluoperazine, fluphenazine, prochlorperazine, and perphenazine. Drug Metab Dispos. 3:437-444

Hals P-A, Dahl SG (1984): Dopaminergic $\mathrm{D}_{2}$ receptor binding of phenothiazine drugs and their metabolites. Nord Psykiatr Tidsskr 10 Suppl.: 17-20

Harris PQ, Friedman MJ, Cohen BM, Cooper TB (1982): Fluphenazine blood levels and clinical response. Biol Psychiatry $17: 1,123-1,130$

Jackson CJC, Hubbard JW, Midha KK (1991): Biosynthesis and characterization of glucuronide metabolites of fluphenazine: 7-hydroxy fluphenazine glucuronide and fluphenazine glucuronide. Xenobiotica 21:383-393

Jann MW, Lam YWF, Chang WH (1990): Reversible metabolism of haloperidol and reduced haloperidol in Chinese schizophrenic patients. Psychopharmacology 101:107111

Janssen PAJ, Awouters FHL (1994): Is it possible to predict the clinical effects of neuroleptics from animal data? Arzneim Forsch 44:269-277

Jaworski T, Hawes EM, McKay G, Midha KK (1990): The metabolism of chlorpromazine $\mathrm{N}$-oxide in man and dog. Xenobiotica 20:107-115

Koreen AR, Lieberman J, Alvir J, Chakos M, Loebel A, Cooper T, Kane J (1994): Relationship of plasma fluphenazine levels to treatment response and extrapyramdal side-effects in first-episode schizophrenic patients. Am J Psychiatry 151:35-39

Korpi ER, Costakos DT, Wyatt RJ (1985): Interconversions of haloperidol and reduced haloperidol in guinea pig and rat liver microsomes. Biochem Pharmacol 16: 2,923-2,927
Kula NS, George T, Baldessarini RJ (1992): Rate of recovery of $D_{1}$ and $D_{2}$ dopamine receptors in young vs adult rat striatal tissues following alkylation with ethoxyzarbonylethoxy-dihydro-quinoline (EEDQ). Dev Brain Res 66:286-289

Lewis MH, Widerlov E, Knight DL, Kilts CD, Mailman RB (1983): N-Oxides of phenothiazine antipsychotics: Effects on in vivo and in vitro estimates of dopaminergic function. J Pharmacol Exp Ther 225:539-545

Lin G, McKay G, Midha KK (1995): Characterization of metabolites of clozapine $\mathrm{N}$-oxide in the rat by micro-column HPLC/MS with electrospray interface. Xenobiotica (submitted)

Marder SR, Van Putten T, Aravagiri M, Hubbard JW, Hawes EM, McKay G, Midha KK (1989): Plasma levels of parent drug and metabolites in patients receiving oral and depot fluphenazine. Psychopharmacol Bull 25:479-482

McKay G, Sleeves T, Cooper JK, Hawes EM, Midha KK (1990): Development and application of a radioimmunoassay for fluphenazine based on monoclonal antibodies and its comparison with alternate assay methods. J Pharm Sci 79:240-243

Midha KK, Hawes EM, Hubbard JW, Korchinski ED, McKay $G$ (1987): The search for correlations between neuroleptic plasma levels and clinical outcome. A critical review. In Meltzer HY (ed), Psychopharmacology. The Third Generation of Progress. New York, Raven, pp 1,3411,351

Midha KK, Hawes EM, Hubbard JW, McKay G, Raw G, Sordes MS, Aravagiri M, Moire MD (1988): Radioimmunoassay for fluphenazine sulfoxide in human plasma. J Pharmacol Methods 19:63-74

Morel E, Lloyd KG, Dahl SG (1987): Antidopaminergic effects of phenothiazine drug metabolites. Psychopharmacology $92: 68-72$.

Sunderland T, Cohen BM (1986): Blood to brain distribution of neuroleptics. Psychiatry Res 20:299-305

Swendsen C, Bird ED (1986): HPLC with electrochemical detection to measure chlorpromazine, thioridazine, and metabolites in human brain. Psychopharmacology 90:316321

Teicher MH (1983): Med-65 ALLFIT, GRAPHIC (Applesoft). Vanderbilt University Biomedical Computing Technology Information, Nashville, TN

Tsuneizumi T, Babb SM, Cohen BM (1992): Drug disposition between blood and brain as a determinant of antipsychotic drug effects. Biol Psychiatry 32:817-824

Van Putten T, Marder SR, Wirshing WC, Aravagiri M, Chabert N (1991): Neuroleptic plasma levels. Schizophrenia Bull 17:197-216

Yamada K, Furukawa T (1980): Behavior of rats and mice administered active metabolites of fluphenazine, 7-hydroxyfluphenazine and fluphenazine-sulfoxide. Arch Int Pharmacodyn 248:76-85 